\title{
Rapid and Simple Analysis of N-Aspartylchlorin e6 (Talaporfin) Using Fluorescence Microtiterplate and Its Application for Determination in Cells, Tissues and Blood
}

\author{
Hiroko Yokoyama ${ }^{1,2}$, Miyabi Ebara ${ }^{1}$, Fuyuki Nakamura ${ }^{1}$, Aina Nanasawa ${ }^{1}$, Sachiko Tanaka ${ }^{1}$, \\ Kenji Onda $^{1}$, Kentaro Sugiyama ${ }^{1}$, Kazuhiko Kasuya ${ }^{3}$, Gulimire Muhetaer ${ }^{1,4}$, Motohide Shimazu ${ }^{4}$, \\ Toshihiko Hirano ${ }^{1}$
}

${ }^{1}$ Department of Clinical Pharmacology, Tokyo University of Pharmacy and Life Sciences, Tokyo, Japan; ${ }^{2}$ The Department of Pharmacy, Kitasato University East Hospital, Sagamihara, Kanagawa, Japan; ${ }^{3}$ Department of 3rd Surgery, Tokyo Medical University, Shinjuku, Tokyo, Japan; ${ }^{4}$ Department of 5th Surgery, Hachioji Medical Center, Tokyo Medical University, Tokyo, Japan.

Email: hiranot@toyaku.ac.jp

Received July $20^{\text {th }}, 2012$; revised August $25^{\text {th }}, 2012$; accepted September $5^{\text {th }}, 2012$

\begin{abstract}
$\mathrm{N}$-aspartylchlorin e6 (talaporfin) concentrations in cancer cells, mouse liver tissues, and human plasma specimens were determined with fluorescence microtiter plate analysis. Talaporfin standard curves were obtained in each of the sample specimens of cells, mouse tissues, or human plasma including serial concentration of talaporfin. The correlation co-efficiencies $\left(\mathrm{r}^{2}\right)$ of talaporfin standard curves were $0.99-1.00$, and the CV less than 5\%. Talaporfin incorporation into cells of human breast cancer cell line MCF-7 after incubating with $25 \mu \mathrm{g} / \mathrm{mL}$ talaporfin for up to $24 \mathrm{~h}$ revealed that the t-max of the drug incorporation was approximately $5 \mathrm{~h}$, and the maximum drug concentration incorporated was 25 $\mu \mathrm{g} / 10^{7}$ cells. Talaporfin incorporation into MCF-7 cells was significantly decreased in the presence of $3 \mu \mathrm{g} / \mathrm{mL}$ cyclosporine $(\mathrm{p}<0.05)$. Balb/c nu/nu mice implanted human cholangiocarcinoma NOZ cells in liver were administered intravenously $5 \mathrm{mg} / \mathrm{mouse}$ of talaporfin, and the tissues of normal liver and tumor, as well as plasma specimens, were analyzed for talaporfin concentrations. The mean (SD) of talaporfin concentration in plasma after 30 min of administration was $41.6(2.3) \mu \mathrm{g} / \mathrm{mL}$, while the level decreased to undetectable concentrations $2 \mathrm{~h}$ after administration. In contrast, the talaporfin concentrations in normal and tumor tissues after $30 \mathrm{~min}$ of administration were $1.1-7.8 \mu \mathrm{g} / \mathrm{g}$ tissue, and the level slightly increased or was almost maintained for up to $2-4 \mathrm{~h}$ after administration. The heparinized blood of the healthy subjects was incubated with $25 \mu \mathrm{g} / \mathrm{mL}$ talaporfin for up to $24 \mathrm{~h}$. The plasma talaporfin concentration did not significantly change during the incubation, and thus talaporfin appears not to be incorporated into the blood cells. We established rapid and simple analysis procedures of talaporfin in biological specimens using a fluorescence microtiter plate assay. Using this assay procedure, the unique pattern of talaporfin disposition and pharmacokinetics were revealed in human cancer cells, liver tissues of tumor bearing mice, and human blood.
\end{abstract}

Keywords: N-Aspartylchlorin E6 (Talaporfin); Fluorescence Microtiterplate Analysis; Breast Tumor Cells; Tumor-Bearing Mouse; Human Plasma

\section{Introduction}

Photodynamic therapy is one of the unique and effective ways for treatment of cancer, and photodynamic therapy alone or in combination with standard therapeutic or palliative modalities is increasingly being utilized for the treatment of several malignancies [1-4]. Photodynamic therapy employs a photosensitizing agent that is activated by light of a specific wavelength to produce reactive oxygen $[5,6]$. Such oxygen species kill cancer cells by inducing apoptosis or necrosis and by damaging tumor vasculature. A common light source for photodynamic therapy is a laser that can be introduced through an en- doscope into the malignant tissues [7], since the light needed to activate photosensitizers cannot pass through more than $5-10 \mathrm{~mm}$ of tissue.

The photosensitizing agent porfimer sodium is most commonly used for photodynamic therapy. The pharmacokinetic profile of porfimer has been previously assessed in five cancer patients, and after a 2-mgkg dose of porfimer sodium, the elimination half-life was reported to be around $283 \mathrm{~h}$ or 11.8 days [8]. Accordingly, skin photosensitization in patients after photodynamic therapy with porfimer sodium is one of the problems for using this agent [9]. The half-life of talaporfin, a porfimer de- 
rivative, in skin appears to be shorter than that of porfimer sodium [10]. The pharmacokinetics of talaporfin elimination from plasma have been reported to be consistent with a two-compartment model with half-lives of

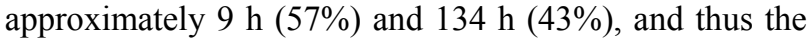
agent, instead of porfimer sodium, has recently been used for photodynamic therapy having benefits with less skin photosensitizing side effects [11].

The determination of talaporfin in biological specimens has generally been carried out using HPLC [11], however the procedure appears to be tedious and time consuming for the analysis of the agent when used on a large number of clinical samples. As such, the present study was undertaken to develop a rapid and simple means of analysis of talaporfin using a fluorescence microtiter plate. We will also report on its application for talaporfin determination in mouse tissues, human tumor cells, and human plasma.

\section{Materials and Methods}

\subsection{Reagents}

Talaporfin was kindly provided from Meiji Co., Ltd. (Tokyo, Japan). Talaporfin was dissolved at a concentration of $500 \mu \mathrm{g} / \mathrm{mL}$ with distilled water immediately before use, and diluted to working concentrations by distilled water, under shaded conditions. RPMI-1640 medium and fetal bovine serum were purchased from Gibco BRL Co. (Grand Island, NY, USA). MEM $\alpha$ medium, MEBM medium, human epidermal growth factor, insulin, and hydrocortisone were from Lonza Japan Co. (Tokyo, Japan). Cell Lysis solution and trypan blue were purchased from Sigma Chemical Co. (St. Louis, MO, USA). Cholera toxin was from Wako Pure Chemicals Co., Tokyo, Japan. Sterilized plastic plates for cell cultures were obtained from Iwaki Co. (Tokyo, Japan). All other reagents were of the best available grade.

\subsection{Cell Culture and Talaporfin Incorporation into Cells}

The template is used to format your paper and style the Human breast cancer cell line MCF-7 cells and normal human-breast cell line 184B5 cells were obtained from Riken BRC Co. (Ibaraki, Japan). MCF-7 cells were maintained in MEM $\alpha$ medium containing $10 \%$ fetal bovine serum, 100 units $/ \mathrm{mL}$ penicillin, and $100 \mu \mathrm{g} / \mathrm{mL}$ streptomycin. 184B5 cells were maintained in MEBM medium containing bovine pituitary extract, human epidermal growth factor, insulin, hydrocortisone, and $1 \mathrm{ng} /$ $\mathrm{mL}$ cholera toxin. These cells at densities of $1-5 \times 10^{5}$ cells $/ \mathrm{mL}$ suspended with each medium were incubated in $5 \% \mathrm{CO}_{2} /$ air at $37^{\circ} \mathrm{C}$ for $3-4$ days in a humidified chamber.
To establish talaporfin standard curves, the cells as maintained above were washed three times with phosphate-buffered saline, detached from the plate with $0.25 \%$ trypsin-EDTA, and resuspended with the above respective medium. The cell number of the cell suspendsion was adjusted to $1-5 \times 10^{5}$ living cells $/ \mathrm{mL}$, by counting living cells with a trypan-blue dye exclusion test [12]. Then, the cells were collected by centrifugation, and lysed with $400 \mu \mathrm{L}$ Cell Lysis Solution (Sigma, USA). Subsequently, $98 \mu \mathrm{L}$ of this cell suspension were placed in each well of a 96-well flat-bottom plate, and two microliters of the solution containing talaporfin were added to yield final talaporfin concentrations of $0.005,0.025$, $0.05,0.1,0.25,0.5,1.0$, and $2.5 \mu \mathrm{g} / \mathrm{mL}$, respectively. The cell suspensions were mixed and then the plate-wells read with fluorescence microplate reader Safire (Techan Co., Tokyo, Japan) at excitation and emission fluorescence levels set at 405 and $665 \mathrm{~nm}$, respectively. Standard linear regression curves were made with the means of the data obtained from at least three independent experiments. The dynamic range of the assay was 0.025 $2.5 \mu \mathrm{g} / \mathrm{mL}$.

To examine talaporfin incorporation into cells, MCF-7 cells or 184B5 cells prepared as descried above were suspended with the medium containing each concentration of talaporfin to cell densities of $1-5 \times 10^{5}$ living cells $/ \mathrm{mL}$, and $2.5 \mathrm{~mL}$ of the cell suspension were placed in a 6-well flat bottom plate. Then, the cells were incubated for $1-24 \mathrm{~h}$ in $5 \% \mathrm{CO}_{2} /$ air at $37^{\circ} \mathrm{C}$ in a humidified chamber. After the incubation, the cells were washed twice with phosphate-buffered saline, detached from the plate with $0.25 \%$ trypsin-EDTA, resuspended with 3.5 $\mathrm{mL}$ medium, and the cell number was counted. Subsequently, the cells were centrifuged at $1300 \mathrm{rpm}$ for $5 \mathrm{~min}$, washed with phosphate-buffered saline, and lysed with $400 \mu \mathrm{L}$ Cell Lysis Solution. The cell lysates were mixed with micro mixer and read with a fluorescence micro titer plate reader for their fluorescence absorbance at excitation and emission fluorescence levels set at 405 and 665 $\mathrm{nm}$, respectively. The amounts of talaporfin incorporated into the cells were determined from the fluorescence data using the talaporfin standard curves.

\subsection{Determination of Talaporfin in Sera and Tissues of Tumor Bearing Mice}

An animal model of tumor bearing mice was established by intrahepatically implanting cells of human cholangiocarcinoma cell line NOZ to 4-week-old male

$\mathrm{BALB} / \mathrm{c} \mathrm{nu} / \mathrm{nu}$ mice [13]. In brief, the $\mathrm{NOZ}$ cells suspended in $100 \mu \mathrm{L}$ of serum-free DMEM medium were inoculated subcutaneously in the back of the male nude mice. After a certain tumor size was reached, the tumor was extracted and formed into $1 \times 1 \times 1 \mathrm{~mm}$ pieces after 
having necrotic tissue removed (NOZ-tumor piece). Another nude mouse was anesthetized and a laparotomy was done. A small tissue pocket was prepared on the surface of the liver as an implantation bed using microscissors. The NOZ-tumor piece was then retransplanted into the pocket, and fixed with 7 - 0 Prolene (Ethicon, Inc., Somerville, NJ, USA). Seven days after the implanting, $5 \mathrm{mg} / \mathrm{kg}$ bodyweight of talaporfin with a sample volume of $200 \mu \mathrm{L}$ dissolved in saline was injected into the caudal vein of the animals. A same volume of saline was injected into the control mice $(\mathrm{n}=3)$. Thirty minutes $(\mathrm{n}=3), 2 \mathrm{~h}(\mathrm{n}=3), 4 \mathrm{~h}(\mathrm{n}=3)$, and $24 \mathrm{~h}(\mathrm{n}=2)$ after talaporfin administration, talaporfin concentrations in serum samples diluted by 20 times with distilled water or $1 \%$ tissue homogenates of normal liver, peritumoral liver, and tumor were measured by the microtiter plate assay procedure as described above. For preparing tissue homogenate, liver specimens were cut into pieces, suspended in distilled water to $0.1 \mathrm{~g} / 10 \mathrm{~mL}$, and homogenized with an ultrasound homogenizer UR-20P (Tomy Seiko, Co., Tokyo, Japan). Standard curves for the determination of talaporfin were made using serum specimens diluted 20 times with distilled water or $1 \%$ homogenate of each tissue specimen obtained from the control mice. Animals were kept at the Animal Care and Use Facilities at Tokyo Medical University Hospital under specific pathogen-free conditions. All experiments were approved by the Animal Care and Ethics Committee of Tokyo Medical University.

\subsection{Determination of Talaporfin in Human Plasma}

After informed consent was obtained, venous blood samples were taken from six healthy subjects (three males and three females; mean age 25.7 years). One milliliter of peripheral blood obtained from healthy subjects was heparinized and incubated at $37^{\circ} \mathrm{C}$ in the dark with 25 $\mu \mathrm{g} / \mathrm{mL}$ talaporfin for $10,30,60$, or $120 \mathrm{~min}$, and $24 \mathrm{~h}$. After each incubation time, the blood was centrifuged at $1500 \mathrm{rpm}$ for $5 \mathrm{~min}$, and the talaporfin concentrations in the plasma were measured by the microtiter plate assay procedure as described above. Standard curves for the determination of talaporfin were made using plasma obtained from each healthy subject, which was diluted 20 times with distilled water.

\subsection{Statistics}

The amounts of talaporfin incorporated into cells or tissues among multiple measurements were compared by Bonferroni test. These analyses were performed with Graph Pad Prism 4.0. In each case, p-values less than 0.05 were considered to be significant.

\section{Results}

\subsection{Talaporfin Incorporation into Human Breast Cancer Cells and Normal Breast Cells}

A typical example of the standard curves for the determination of talaporfin added in the cell culture of the normal human breast cell line 184B5 is presented in Figure 1. As shown in this figure, the correlation coefficiencies $\left(r^{2}\right)$ of talaporfin standard curves made using biofluids in the present study were $0.99-1.00$, and the $\mathrm{CV}$ less than $5 \%$.

Then, we examined the incorporation of talaporfin into the cells of the breast cancer cell line MCF-7 and the normal breast cell line 184B5 in vitro (Figure 2). MCF-7 cells were incubated with $25 \mu \mathrm{g} / \mathrm{mL}$ talaporfin for up to $24 \mathrm{~h}$, and the agent concentration incorporated in the cells was determined with fluorescence microtiter plate analysis after cell lyses without the extraction of the drug. Talaporfin incorporation into the cells of the human breast cancer cell line MCF-7 after incubating with talaporfin revealed that the $t$-max of the drug incorporation was approximately $5 \mathrm{~h}$, and the maximum drug amount incorporated was $25 \mu \mathrm{g} / 10^{7}$ cells (Figure 2(a)). The talaporfin incorporation into the cells slightly decreased at $24 \mathrm{~h}$ of incubation to approximately $20 \mu \mathrm{g} / 10^{7}$ cells. Talaporfin incorporation was also examined using the normal human breast cell line 184B5 cells (Figure 2(b)). 184B5 cells were incubated for up to $24 \mathrm{~h}$ in the presence of $25 \mu \mathrm{g} / \mathrm{mL}$ talaporfin, and the agent concentration in cells was measured in the same manner with the microtiter plate assay procedures. The drug incorporation line-

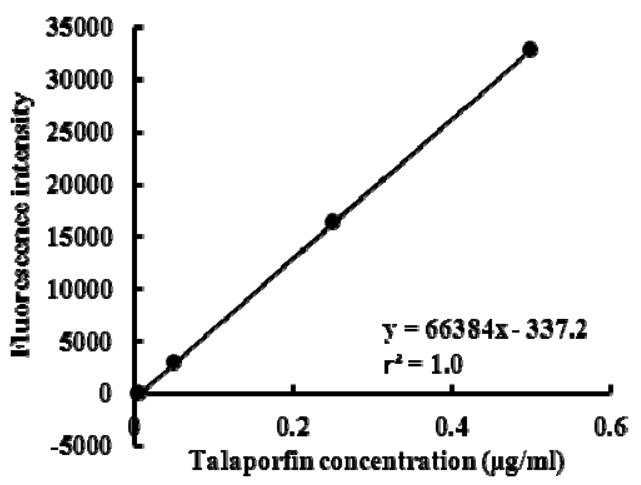

Figure 1. A typical talaporfin standard curve for the determination of the agent in the cells of normal human breast cell line 184B5. Cells were collected by centrifugation, and lysed with Cell Lysis Solution. Subsequently, talaporfin was added to yield final concentrations of $0.005,0.05,0.25$, and $0.5 \mu \mathrm{g} / \mathrm{mL}$, respectively, in 96 well microtiter plate. The solutions were mixed and then the plate-wells read with a fluorescence microplate reader. Standard linear regression curves were made with means of the data obtained from three independent wells. 


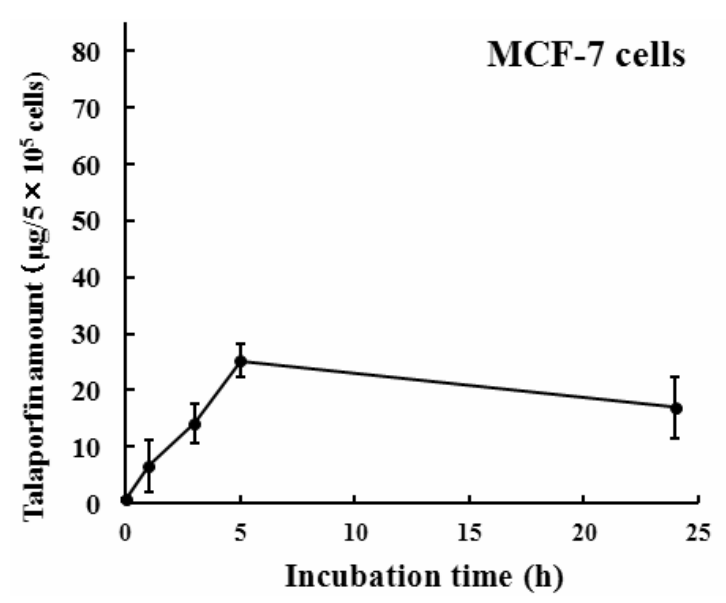

(a)

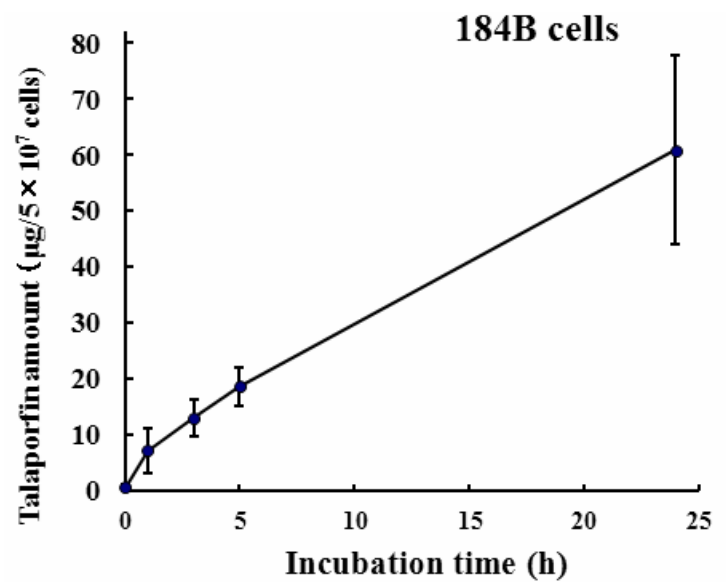

(b)

Figure 2. Time-dependent incorporation of talaporfin into the cells of human breast cancer cell line MCF-5 (a) and the normal human breast cell line $184 \mathrm{B5}$ (b). The cells were incubated with $25 \mu \mathrm{g} / \mathrm{mL}$ of talaporfin for up to $24 \mathrm{~h}$, and the agent concentration incorporated in the cells was determined at the indicated times with fluorescence microtiter plate analysis after cell lyses. The data are indicated as the means of five or six independent experiments.

arly increased depending on the incubation time to $24 \mathrm{~h}$, and the amount of talaporfin incorporated was $60 \mu \mathrm{g} / 10^{7}$ cells at $24 \mathrm{~h}$. Thus, the kinetic pattern of talaporfin incorporation was different between the human breast cancer cells and the normal breast cells.

We also examined the effect of cyclosporine, which is known as an inhibitor of drug-transporters such as P-glycoprotein [14], on the uptake of talaporfin into MCF-7 cells. MCF-7 cells were incubated with 25 $\mu \mathrm{g} / \mathrm{mL}$ talaporfin in the absence or presence of 1 or 3 $\mu \mathrm{g} / \mathrm{mL}$ cyclosporine for $5 \mathrm{~h}$, and talaporfin concentration incorporated into the cells was determined by the fluorescence microtiter plate assay procedures (Figure 3). Cyclosporine at $1 \mu \mathrm{g} / \mathrm{mL}$ resulted in no significant effect on the talaporfin incorporation, whereas $3 \mu \mathrm{g} / \mathrm{mL}$ of cyc-

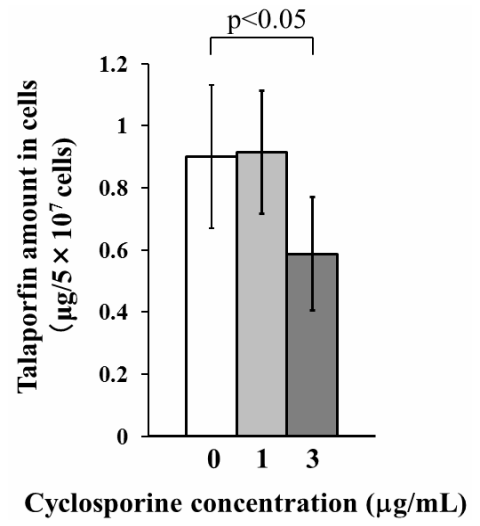

Figure 3. Effect of cyclosporine on the incorporation of talaporfin into MCF-7 cells. MCF-7 cells were incubated with $25 \mu \mathrm{g} / \mathrm{mL}$ talaporfin in the presence of 1 or $3 \mu \mathrm{g} / \mathrm{mL}$ cyclosporine for $5 \mathrm{~h}$, and the cells were collected by centrifugation. The cells were lysed and the talaporfin concentration was determined by the fluorescence microtiter plate assay procedures. $p<0.05$ as compared to the level of control (cyclosporine free) by the Bonferroni test.

losporine significantly attenuated the incorporation, as compared to the control (without cyclosporine) $(\mathrm{p}<0.05$; Figure 3).

\subsection{Talaporfin Distribution in Sera and Tissues of Tumor Bearing Mice}

Balb/c nu/nu mice implanted with human cholangiocarcinoma NOZ cells into the liver were intravenously administered $5 \mathrm{mg} / \mathrm{mouse}$ of talaporfin, and the tissues of the normal liver and tumor, as well as plasma specimens, were analyzed for talaporfin concentrations. The tumor sizes in the liver of these animals were approximately 50 $\mathrm{mm}^{3}$. Talaporfin concentration in the sera reached their maximum level at $30 \mathrm{~min}$ after administration, and the level decreased to undetectable concentrations at $2-24 \mathrm{~h}$ after administration (Figure 4(a)). The mean (SD) of talaporfin concentration in plasma after $30 \mathrm{~min}$ of ad0 ministration was $41.6(2.3) \mu \mathrm{g} / \mathrm{mL}$. In contrast, talaporfin concentration levels in the normal and peritumoral liver tissues after $30 \mathrm{~min}$ of administration were approximately $1.1-7.8 \mu \mathrm{g} / \mathrm{g}$ tissue, and the level slightly increased or was almost maintained thereafter for up to 2 - $4 \mathrm{~h}$ of administration (Figures 4(b) and (c)). The level decreased to $0.9-2.1 \mu \mathrm{g} / \mathrm{g}$ tissue at $24 \mathrm{~h}$ after administration. In the tumor tissues, talaporfin incorporation appears to be a maximum of $2.5 \mu \mathrm{g} / \mathrm{g}$ tissue at $2 \mathrm{~h}$. The data for the incorporated amounts into the tumor tissue showed individual differences between animals, especially at $4 \mathrm{~h}$ after administration (Figure 4(d)).

\subsection{Distribution of Talaporfin in Human Blood}

One milliliter of peripheral blood of healthy subjects $(n=$ 


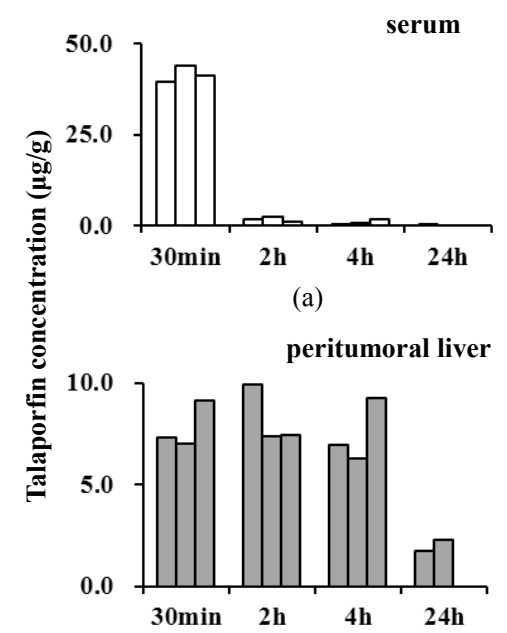

(c)

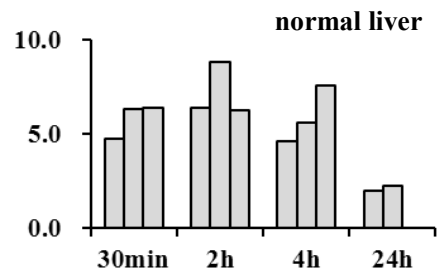

(b)

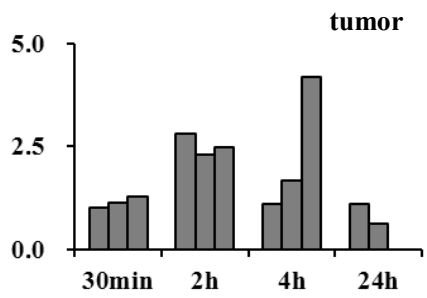

(d)

Time after administration

Figure 4. Talaporfin concentrations in serum (a), normal liver (b), peritumoral liver (c), and tumor (d), in mice having implanted NOZ human bile duct cancer. Balb/c nu/nu mice implanted human cholangiocarcinoma NOZ cells into liver were administered intravenously $5 \mathrm{mg} / \mathrm{mouse}$ of talaporfin, and the agent concentration in sera and tissues after $0.5(\mathrm{n}=3), 2(\mathrm{n}=$ 3), $4(n=3)$, and $24(n=2)$ h of administration were analyzed with fluorescence microtiter plate analysis. Each bar indicates the concentration of talaporfin in the serum or tissues of one animal.

6) was heparinized and incubated with $25 \mu \mathrm{g} / \mathrm{mL}$ talaporfin for up to $24 \mathrm{~h}$. After the indicated incubation time, the blood was centrifuged, and talaporfin concentrations in the plasma were measured by the microtiter plate assay procedures (Figure 5). Plasma talaporfin concentration slightly decreased according to the incubation time, but the concentration was not significantly changed during the incubation time. Thus, the data suggest that a small amount of talaporfin was incorporated into the human blood cells.

\section{Discussion}

The present study was undertaken to develop a rapid and simple means of analysis of talaporfin using fluorescence microtiter plate assay procedures for the determination of the agent in several biological specimens. The correlation co-efficiencies $\left(\mathrm{r}^{2}\right)$ of the talaporfin standard curves were $0.99-1.00$, and thus the assay is thought to be applicable for the determination of talaporfin in biological specimens including patient's blood or tissues. Indeed, using this assay procedure, unique patterns of talaporfin disposition and pharmacokinetics were revealed in human cancer cells, sera or tissues of tumor bearing mice, and human blood.

The kinetic analysis of talaporfin incorporation into human breast cancer cells and normal breast cells in vitro (Figure 2) showed that the incorporation pattern was different between the breast cancer cells and the normal breast cells, and that the incorporation in cancer cells reached their maximum at approximately $5 \mathrm{~h}$, which was

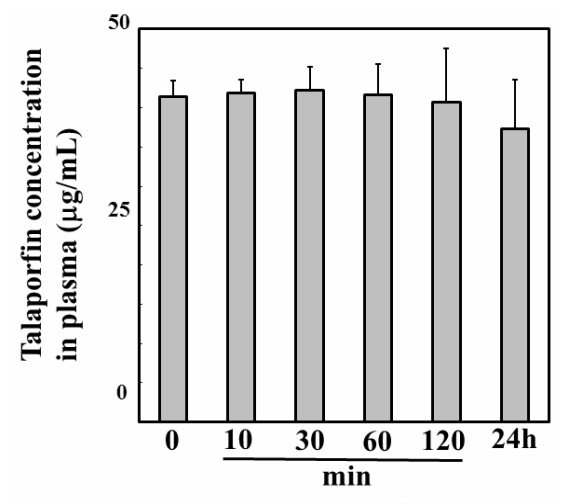

Incubation time

Figure 5. Talaporfin concentrations in plasma of healthy subjects after the addition of the agent to heparinized whole blood in vitro. Venous blood of healthy subjects was heparinized, and incubated in tubes containing a final concentration of $25 \mu \mathrm{g} / \mathrm{mL}$ talaporfin for the indicated time at $37^{\circ} \mathrm{C}$. After incubation, the tube was centrifuged, and talaporfin concentration in plasma was measured with fluorescence microtiter plate analysis. The data are indicated as mean (SD) of the data of six blood specimens obtained from six independent healthy subjects.

much earlier than that in the normal cells. The results suggest that the distribution of talaporfin into the breast cancer and normal breast tissues is time dependent, and therefore the timing of light sensitization after the administration of talaporfin appears to be critical for efficient photodynamic therapy with less toxicity to normal breast tissue. It has been reported that, in photodynamic therapy for lung cancer, photosensitization is efficiently 
carried out at $4-6 \mathrm{~h}$ after intravenous administration of talaporfin [15]. These findings are consistent with our present observations that talaporfin incorporation into tumor cells would reach their maximum after $4-6 \mathrm{~h}$ of administration, and photosensitization during this period (4 - $6 \mathrm{~h}$ after administration) is quite appropriate. Usuda et al. reported that talaporfin based photodynamic therapy in lung cancer patients exhibited a strong antitumor effect, regardless of the expression status of breast cancer resistant protein (BCRP) in cancer tissues resected from patients [16]. Moreover, they also suggested that photofrin is a substrate of BCRP and be pumped out from the cells, therefore, BCRP may be a molecular determinant of the outcome of photofrin-based photodynamic therapy [16]. Cyclosporine is known as an inhibitor of drugtransporters such as P-glycoprotein [14]. The inhibition of P-glycoprotein by cyclosporine has been reported to result in a decrease of efflux of the agent from the cells, and therefore an increase in the cellular concentration of the agents [14]. In the present study, however, cyclosporine at $3 \mu \mathrm{g} / \mathrm{mL}$ resulted in the significant inhibition of the talaporfin incorporation into MCF-7 cells $(p<0.05)$ (Figure 3). Though the underlying mechanism(s) remained to be elucidated, cyclosporine may attenuate the uptake of talaporfin into MCF-7 through the inhibition of an unknown cellular transporter, which may mediate talaporfin uptake into cells.

The pharmacokinetic study of talaporfin after intravenous administration in tumor-bearing mice (Figure 4) showed the rapid clearance of the agent from the serum and concomitant increase in the level in the liver and tumor tissues. In this tumor-bearing mice model, time dependence for the distribution of talaporfin also appears to be different between normal liver and tumor tissues. In contrast, our data suggested that a small amount of talaporfin is incorporated into human blood cells (Figure 5), which may be consistent with the data for rapid serum-clearance of the agent in the tumor-bearing mice model.

Photodynamic therapy is increasingly being utilized for the treatment of several malignancies [2-6]. The half-life of talaporfin in human tissues is shorter than that of porfimer sodium, and the pharmacokinetics of talaporfin elimination from plasma have been reported to be consistent with a two-compartment model with half-lives of approximately 9 and $134 \mathrm{~h} \mathrm{[11].}$

Thus the agent, instead of porfimer sodium, has recently been used for photodynamic therapy having benefits with less photosensitizing side effects [11]. However, blood and tumor-tissue distribution of talaporfin after intravenous administration of the agent has not been investigated thoroughly to the best of our knowledge, probably because there has been no analytical method with a simple and rapid procedure for surveying a large number of clinical samples. HPLC is generally used for talaporfin determination [11], but the procedures require the extraction of talaporfin from biological fluids to concentrate the agent, and is time consuming. Therefore, though the technique is accurate and reliable, HPLC appears not to be suitable for the determination of talaporfin in clinical biofluids or tissues for the carrying out individualized photodynamic therapy with talaporfin. The fluorescence microtiter plate analysis of talaporfin presently established can provide real time data for the clinical pharmacokinetic analysis of the agent during photodynamic therapy by talaporfin. The time requiring determination of talaporfin in human serum would be less than 10 minutes for 96 specimens in one microtiter plate, and the amount of serum required would be less than $100 \mu \mathrm{L}$.

The present study, in summary, provided a rapid and simple procedure for talaporfin analysis in biological specimens using a fluorescence microtiter plate assay. We showed, by this assay procedure, the unique pattern of talaporfin disposition and pharmacokinetics in human cancer cells, liver tissues of tumor bearing mice, and human blood.

\section{REFERENCES}

[1] Y. W. Kim, S. M. Bae, G. Battogtokh, H. J. Bang and W. S. Ahn, "Synergistic Anti-Tumor Effects of Combination of Photodynamic Therapy and Arsenic Compound in Cervical Cancer Cells: In Vivo and in Vitro Studies," PLos One, Vol. 7, No. 6, 2012, p. e38583.

doi:/10.1371/journal.pone.0038583

[2] P. Soergel, G. F. Dahl, M. Onsrud and P. Hillemanns, "Photodynamic Therapy of Cervical Intraepithelial Neoplasia 1-3 and HPV Infection with Methylaminolevulinate and Hexaminolevulinate-A Double-Blind, DoseFinding Study," Lasers in Surgery and Medicine, Vol. 44, No. 6, 2012, pp. 468-474. doi:/10.1002/1sm.22041

[3] R. P. Johnson, C. W. Chung, Y. I. Jeong, D. H. Kang, H. Suh and I. Kim, "Poly (L-Histidine)-Tagged 5-Aminolevulinic Acid Prodrugs: New Photosensitizing Precursors of Protoporphyrin IX for Photodynamic Colon Cancer Therapy," International Journal of Nanomedicine, Vol. 7, 2012, pp. 2497-2512.

[4] M. E. Ortner, K. Caca, F. Berr, J. Liebetruth, U. Mansmann, D. Huster, W. Voderholzer, G. Schachschal, J. Mössner and H. Lochs, "Successful Photodynamic Therapy for Nonresectable Cholangiocarcinoma: A Randomized Prospective Study," Gastroenterology, Vol. 125, No. 5, 2003, pp. 1355-1363. doi:/10.1016/i.gastro.2003.07.015

[5] J. T. Lau, P. C. Lo, W. P. Fong and D. K. Ng, “A Zinc(II) Phthalocyanine Conjugated with an Oxaliplatin Derivative for Dual Chemo- and Photodynamic Therapy," Journal of Medicinal Chemistry, Vol. 55, No. 11, 2012, pp. 
5446-5454. doi:/10.1021/jm300398q

[6] C. B. Simone, J. S. Friedberg, E. Glatstein, J. P. Stevenson, D. H. Sterman, S. M. Hahn and K. A. Cengel, "Photodynamic Therapy for the Treatment of Non-Small Cell Lung Cancer," Journal of Thoracic Disease, Vol. 4, No. 1, 2012, pp. 63-75.

[7] M. L. Davila, "Photodynamic Therapy," Gastrointestinal Endoscopy Clinics of North America, Vol. 21, No. 1, 2011, pp. 67-79. doi:/10.1016/j.giec.2010.09.002

[8] J. M. Houle, N. Clervoix, S. Bain and J. Spénard, "Lack of Effect of Sex and Disease State on the Pharmacokinetics of Porfimer Sodium," Clinical Pharmacokinetics, Vol. 45, No. 9, 2006, pp. 923-930. doi:/10.2165/00003088-200645090-00004

[9] P. Baas, I. van Mansom, H. van Tinteren, F. A. Stewart and N. van Zandwijk, "Effect of N-Acetylcysteïne on Photofrin-Induced Skin Photosensitivity in Patients," Lasers in Surgery and Medicine, Vol. 16, No. 4, 1995, pp. 359-367. doi:/10.1002/1sm.1900160407

[10] T. A. Katsumi, K. Aizawa, Y. Kuroiwa, K. Saito, Y. Kurata, Y. Ii, T. Okunaka, C. Konaka and H. Kato, "Photodynamic Therapy with a Diode Laser for Implanted Fibrosarcoma in Mice Employing Mono-L-Aspartyl Chlorin E6," Photochemistry and Photobiology, Vol. 64, No. 4, 1996, pp. 671-675. doi:/10.1111/j.1751-1097.1996.tb03122.x

[11] D. Kessel, "Pharmacokinetics of N-Aspartyl Chlorin E6 in Cancer Patients," Journal of Photochemistry and Photobiology B: Biology, Vol. 39, 1997, pp. 81-83. doi:/10.1016/S1011-1344(96)00009-7

[12] X.-M. Hu, T. Hirano and K. Oka, "Arsenic Trioxide Induces Apoptosis Equally to T Lymphoblastoid Leukemia
MOLT-4 Cells and P-gp Expressing Daunorubicin-Resistant MOLT-4 Cells," Cancer Chemotherapy and Pharmacology, Vol. 51, No. 2, 2003, pp. 119-126. doi:/10.1007/s00280-003-0629-5

[13] K. Kasuya, M. Shimazu, M. Suzuki, Y. Kuroiwa, J. Usuda, T. Itoi, A. Tsuchida and T. Aoki, "Novel Photodynamic Therapy against Biliary Tract Carcinoma Using MonoL-Aspartyl Chlorine E6: Basic Evaluationfor Its Feasibility and Efficacy," Journal of Hepato-Biliary-Pancreatic Surgery, Vol. 17, No. 3, 2010, pp. 313-321. doi:/10.1007/s00534-009-0246-8

[14] Z.-L. Liu, T. Hirano, S. Tanaka, K. Onda and K. Oka, "Persistent Reversal of P-Glycoprotein-Mediated Daunorubicin Resistance by Tetrandrine in Multidrug-Resistant Human T Lymphoblastoid Leukemia MOLT-4 Cells," Journal of Pharmacy and Pharmacology, Vol. 55, No. 11, 2003, pp. 1531-1537. doi:/10.1211/0022357022115

[15] J. Usuda, S. Ichinose, T. Ishizumi, H. Hayashi, K. Ohtani, S. Maehara, S. Ono, H. Honda, N. Kajiwara, O. Uchida, H. Tsutsui, T. Ohira, H. Kato and N. Ikeda, "Outcome of Photodynamic Therapy Using NPE6 for Bronchogenic Carcinomas in Central Airways $>1.0 \mathrm{~cm}$ in Diameter," Clinical Cancer Research, Vol. 16, No. 7, 2010, pp. 2198-2204. doi:/10.1158/1078-0432.CCR-09-2520

[16] J. Usuda, S. Ichinose, T. Ishizumi, H. Hayashi, K. Ohtani, S. Maehara, S. Ono, H. Honda, N. Kajiwara, O. Uchida, H. Tsutsui, T. Ohira, H. Kato and N. Ikeda, "Breast Cancer Resistant Protein (BCRP) is a Molecular Determinant of the Outcome of Photodynamic Therapy (PDT) for Centrally Located Early Lung Cancer," Lung Cancer, Vol. 67, No. 2, 2010, pp. 198-204 doi:/10.1016/j.lungcan.2009.04.002 